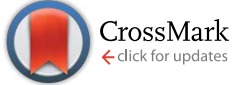

Cite this: J. Mater. Chem. A, 2015, 3, 7554

Received 1st January 2015

Accepted 25th February 2015

DOI: $10.1039 / c 5 t a 00009 b$

www.rsc.org/MaterialsA

\section{Improving the electrochemical performance of layered lithium-rich cathode materials by fabricating a spinel outer layer with $\mathrm{Ni}^{3+}+$}

\author{
Cheng Yang, Qian Zhang, Weixiang Ding, Jun Zang, Ming Lei, Mingsen Zheng* \\ and Quanfeng Dong*
}

Surface modification and fabrication of composite structures have been reported to be efficient strategies to obtain cathode materials with satisfactory electrochemical performance. Herein, a combined method to fabricate an oxidized spinel outer layer containing $\mathrm{Ni}^{3+}$ is demonstrated to be an effective method to improve the rate capability as well as cyclability of Li-rich cathode materials. Such a surface modification process is carried out through a facile treatment with ammonium persulfate, and a homogeneous layeredspinel structure is thus obtained, which contains intimately connected layered bulk and an oxidized spinel outer layer. The thus-obtained material delivers a charge/discharge capacity of $330.5 / 308.7 \mathrm{~mA} \mathrm{~h} \mathrm{~g}^{-1}$, with an enhanced coulombic efficiency up to $93.4 \%$ and a rather fascinating rate capability of $169.1 \mathrm{~mA} \mathrm{~h} \mathrm{~g}^{-1}$, $100.8 \mathrm{~mA} \mathrm{~h} \mathrm{~g}^{-1}$, and $68.2 \mathrm{~mA} \mathrm{~h} \mathrm{~g} \mathrm{~g}^{-1}$ at $10 \mathrm{C}, 20 \mathrm{C}$ and $30 \mathrm{C}$, respectively, and a much superior cycle performance, which is a stable capacity with no fading after prolonged 200 cycles.

\section{Introduction}

The rapidly growing demand for high-energy density and highpower density lithium ion batteries gives great impetus for research on advanced cathode materials. ${ }^{1-3}$ Since first introduced by Dahn et al., ${ }^{4}$ the series of lithium-rich materials, which is expressed as $x \mathrm{Li}_{2} \mathrm{MnO}_{3} \cdot(1-x) \mathrm{LiMO}_{2}(0<x<1, \mathrm{M}=\mathrm{Ni}$, Co, Mn, $\mathrm{Cr}, . .$.$) , has been considered as the most promising cathode$ materials for Li-ion batteries that can be deployed in hybrid electric vehicles (HEVs) and plug-in hybrid electric vehicles (PHEVs). They can deliver a much larger specific capacity of over $250 \mathrm{~mA} \mathrm{~h} \mathrm{~g}{ }^{-1}$ and show a high energy density up to $900 \mathrm{~W} \mathrm{~h} \mathrm{~kg}^{-1}$ with greatly lower cost compared with the present commercial cathode materials, such as $\mathrm{LiCoO}_{2}, \mathrm{LiMn}_{2} \mathrm{O}_{4}$, etc. ${ }^{5,6}$ Yet there are still vital drawbacks like the large irreversible capacity during the first cycle, poor rate capability and stability hindering the layered lithium-rich materials from commercial application..$^{7-9}$

Creating a fast ion-conducting surface phase and fabricating heterostructured materials through controlled off-stoichiometry have been reported to be efficient strategies. They protect the material from reactions with the electrolyte and accelerate the Li ion intercalation/deintercalation process. ${ }^{10,11}$ Such efforts including surface coating (with metal oxides, ${ }^{\mathbf{1 2 - 1 4}}$ metal

Department of Chemistry, College of Chemistry and Chemical Engineering, Xiamen University, State Key Laboratory of Physical Chemistry of Solid Surfaces, Xiamen University, Xiamen, Fujian, 361005, China.E-mail: qfdong@xmu.edu.cn; mszheng@ xmu.edu.cn

$\dagger$ Electronic supplementary information (ESI) available. See DOI: $10.1039 / \mathrm{c} 5$ ta00009b fluorides, metal phosphates, ${ }^{15-17}$ and even binary or ternary components), ${ }^{\mathbf{1 8 , 1 9}}$ acid treatment with dilute acids, surface reduction by hydrogen, ammonia or carbon,,$^{20-23}$ and synthesis of heterostructures like core-shell and concentration-gradient surfaces $^{\mathbf{2 4 - 2 6}}$ have been widely adopted. Since it was reported that a spinel-like phase may improve the rate capability of the cathode material, ${ }^{27}$ several groups fabricated spinel-layered composite-structured materials by a coating or a chemical reduction process, such products were acquired with either a spinel $\mathrm{LiMn}_{2} \mathrm{O}_{4}$ or a reduced $\mathrm{Li}_{1.2} \mathrm{Ni}_{0.13} \mathrm{Co}_{0.13} \mathrm{Mn}_{0.54} \mathrm{O}_{2}$ outer layer. ${ }^{28,29}$ Unfortunately, all these approaches have only improved the rate capability of layered Li-rich cathode materials at the expense of capacity or stability or the other way around.

To fabricate an appropriate structure is still a great challenge. In this paper, an oxidized spinel outer layer containing $\mathrm{Ni}^{3+}$ was fabricated by robust surface modification with ammonium persulfate. The electrochemical performance of the as-obtained material was tested, and the role played by $\mathrm{Ni}^{3+}$ in the composite-structured material was studied.

\section{Experimental}

2.1 Synthesis of pristine and surface modified $\mathrm{Li}_{1.2} \mathrm{Ni}_{\mathbf{0 . 1 3}} \mathrm{Co}_{\mathbf{0 . 1 3}} \mathrm{Mn}_{\mathbf{0 . 5 4}} \mathrm{O}_{2}$

The pristine material of layered $\mathrm{Li}_{1.2} \mathrm{Ni}_{0.13} \mathrm{Co}_{0.13} \mathrm{Mn}_{0.54} \mathrm{O}_{2}$ was synthesized by a sol-gel method. The typical process of $\mathrm{Li}_{1.2^{-}}$ $\mathrm{Ni}_{0.13} \mathrm{Co}_{0.13} \mathrm{Mn}_{0.54} \mathrm{O}_{2}$ synthesis was described in our previous study. ${ }^{30}$ Surface modification on the as-obtained material was implemented as follows: $0.06 \mathrm{~g}$ APS (ammonium persulfate) was dissolved in $15 \mathrm{~mL}$ de-ionized water with stirring; an 
appropriate amount of $\mathrm{Li}_{1.2} \mathrm{Ni}_{0.13} \mathrm{Co}_{0.13} \mathrm{Mn}_{0.54} \mathrm{O}_{2}$ (1.5 g), corresponding to a molar ratio of APS/ $\mathrm{Li}_{1.2} \mathrm{Ni}_{0.13} \mathrm{Co}_{0.13} \mathrm{Mn}_{0.54} \mathrm{O}_{2}$ as $1.5 \%$, was then dispersed in the solution. The as-prepared solution was transferred into a Teflon-lined stainless steel autoclave. The autoclave was then sealed and heated at $120{ }^{\circ} \mathrm{C}$ for $48 \mathrm{~h}$. The obtained substance was filtered, washed, dried and then calcined at $450{ }^{\circ} \mathrm{C}$ for $5 \mathrm{~h}$. Finally the product was ground and collected. The as-obtained material is denoted as APST. For comparison, another sample is obtained in the same way as APST, the only difference is that an equal molar amount of $\left(\mathrm{NH}_{4}\right)_{2} \mathrm{SO}_{4}$ was used instead of $\left(\mathrm{NH}_{4}\right)_{2} \mathrm{~S}_{2} \mathrm{O}_{8}$, and the obtained product is denoted as AST.

\subsection{Material characterization}

The crystal structure of the products was characterized by X-ray powder diffraction (Philips Panalytical X-pert, using $\mathrm{Cu} \mathrm{K} \alpha 1$ radiation $\lambda=1.5405 \AA$ ). The morphology of the products was observed by field-emission scanning electron microscopy (SEM Hitachi S-4800, $15 \mathrm{kV}$ ) and transmission electron microscopy (TEM Hitachi JEM-2100, $200 \mathrm{kV}$ ).

The chemical state of the pristine material and modified samples was determined at room temperature by using an Ion TOF Qtac-100 HSLEISS-XPS spectrometer.

\subsection{Electrochemical measurements}

Electrochemical performances were evaluated with CR2016 coin cells between 4.8 and $2.0 \mathrm{~V}$. The cathodes were prepared by mixing $80 \mathrm{wt} \%$ active materials with $10 \mathrm{wt} \%$ super-P and $10 \mathrm{wt} \%$ water soluble polymer $n$-lauryl acrylate (LA Chengdu, China). Al foil was used as the current collector and Li foil was used as the counter electrode. The electrolyte was $1 \mathrm{M} \mathrm{LiPF}_{6}$ in a $1: 1: 1$ $\mathrm{v} / \mathrm{v} / \mathrm{v}$ mixture of propylene carbonate (PC), ethyl methyl carbonate (EMC) and sulfolane (SL) (Zhuhai, China), and the separator was a Celgard 2400 polypropylene membrane.

Cell assembly was carried out in an Ar-filled glove box with the concentrations of moisture and oxygen below $1 \mathrm{ppm}$. The cells were galvanostatically charged and discharged using a BTS Battery Tester (Neware, Shenzhen, China) at various current densities. Electrochemical impedance spectrometry (EIS) tests were performed on an IM6 (Zahner Elektrik) in the frequency range of $100 \mathrm{kHz}$ to $10 \mathrm{mHz}$.

\section{Results and discussion}

As shown in Fig. 1, a layered-to-spinel transformation reaction at the surface of $\mathrm{Li}_{1.2} \mathrm{Ni}_{0.13} \mathrm{Co}_{0.13} \mathrm{Mn}_{0.54} \mathrm{O}_{2}$ can be induced by leaching some elements or components from the external domain of the host material through a strong oxidation reaction with ammonium persulfate and a subsequent annealing process. In a typical experiment, two points should be emphasized: first, when $\left(\mathrm{NH}_{4}\right)_{2} \mathrm{~S}_{2} \mathrm{O}_{8}$ is adjusted to an appropriate concentration, a $\mathrm{H}^{+}-\mathrm{Li}^{+}$exchange reaction is induced at the surface of $\mathrm{Li}_{1.2} \mathrm{Ni}_{0.13} \mathrm{Co}_{0.13} \mathrm{Mn}_{0.54} \mathrm{O}_{2}$ particle, which leads to a decrease of the Li/TM (transition metal element) ratio. Then a $\mathrm{Li}(\mathrm{TM})_{2} \mathrm{O}_{4}$ phase is likely to form in the subsequent heat treatment. Second, $\mathrm{Ni}^{2+}$ in the

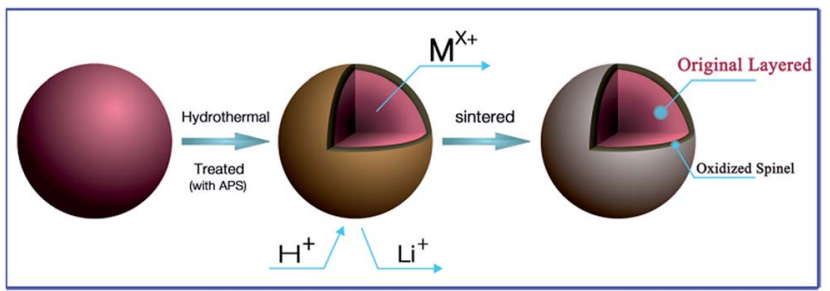

Fig. 1 Schematic illustration of surface modification on $\mathrm{Li}_{1.2} \mathrm{Ni}_{0.13} \mathrm{Co}_{0.13} \mathrm{Mn}_{0.54} \mathrm{O}_{2}$.

$\mathrm{Li}_{1.2} \mathrm{Ni}_{0.13} \mathrm{Co}_{0.13} \mathrm{Mn}_{0.54} \mathrm{O}_{2}$ particle tends to be oxidized by $\left(\mathrm{S}_{2} \mathrm{O}_{8}\right)^{2-}$ rather than $\mathrm{Mn}^{4+}$ and $\mathrm{Co}^{3+} \cdot{ }^{31-33}$ As a result, when a suitable amount of APS is employed, the oxidized spinel outer layer containing $\mathrm{Ni}^{3+}$ is obtained. Since the oxidized spinel outer layer originates from the surface part of the original layered $\mathrm{Li}_{1.2} \mathrm{Ni}_{0.13} \mathrm{Co}_{0.13} \mathrm{Mn}_{0.54} \mathrm{O}_{2}$, the newly formed phase can be intimately connected to the bulk "layered" structure and well compatible with it. In order to clarify that the oxidized spinel outer layer with $\mathrm{Ni}^{3+}$ plays an important role in improving the electrochemical performance of the Li-rich cathode material, pristine $\mathrm{Li}_{1.2} \mathrm{Ni}_{0.13} \mathrm{Co}_{0.13} \mathrm{Mn}_{0.54} \mathrm{O}_{2}$ synthesized by the sol-gel method and surface modified $\mathrm{Li}_{1.2} \mathrm{Ni}_{0.13}$ $\mathrm{Co}_{0.13} \mathrm{Mn}_{0.54} \mathrm{O}_{2}$ with ammonium persulfate (APS) or ammonium sulfate (AS) were studied.

XRD patterns of APST, AST and the pristine material are shown in Fig. 2. The pristine sample shows strong peaks that can be indexed to the layered $(R \overline{3} \mathrm{~m})$ structure of hexagonal $\alpha$ $\mathrm{NaFeO}_{2}$, with weak peaks around $20-25^{\circ}$ corresponding to $\mathrm{LiMn}_{6}$ super-ordering in the $\mathrm{Li}_{2} \mathrm{MnO}_{3}$ monoclinic phase $(\mathrm{C} 2 / \mathrm{m}$, monoclinic). For the modified samples, no extra peaks for mixed phases are observed which is probably because treatment with such a small amount of AS/APS only leads to a rather slight degree of transformation reaction at the surface. It has been reported that the ordering of the structure can be indicated from the XRD patterns with the $I(003) / I(104)$ and the lattice parameter ratios of $c / a$. And by comparing the $I(003) / I(104)$ and $c / a$, both surface treatments lead to a better hexagonal ordering and ion arrangement (see Table S1†). ${ }^{\mathbf{3 4 3 5}}$

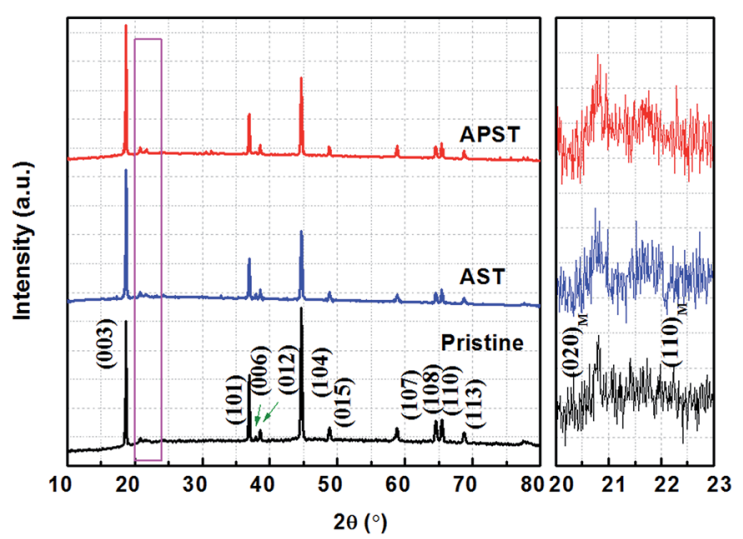

Fig. 2 XRD patterns of the pristine $\mathrm{Li}_{1.2} \mathrm{Ni}_{0.13} \mathrm{CO}_{0.13} \mathrm{Mn}_{0.54} \mathrm{O}_{2}$ material, AST and APST. 


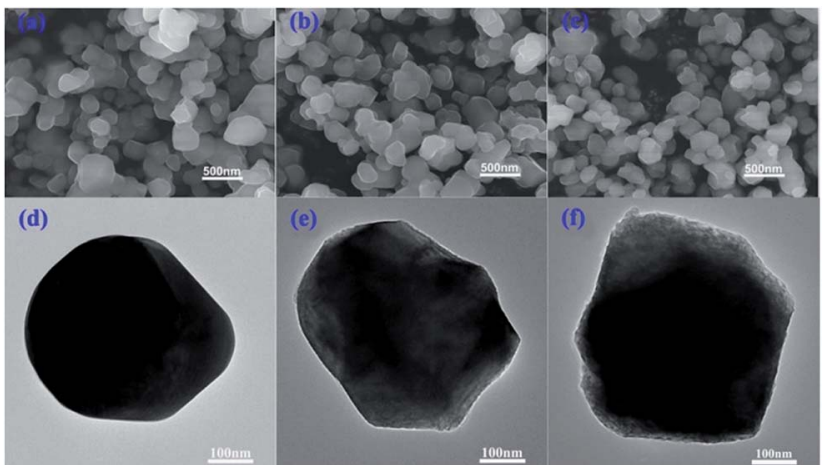

Fig. 3 SEM images of (a) the pristine $\mathrm{Li}_{1.2} \mathrm{Ni}_{0.13} \mathrm{CO}_{0.13} \mathrm{Mn}_{0.54} \mathrm{O}_{2}$ material, (b) AST and (c) APST. TEM images of a single particle of (d) the pristine $\mathrm{Li}_{1.2} \mathrm{Ni}_{0.13} \mathrm{Co}_{0.13} \mathrm{Mn}_{0.54} \mathrm{O}_{2}$ material, (e) AST, and (f) APST.

The morphology and particle size of the pristine sample, AST and APST were examined by using a scanning electron microscope (SEM). As shown in the SEM images in Fig. 3(a)-(c), the size of highly crystallized particles is around 200-500 $\mathrm{nm}$. Evidently, the modified samples do not display a change in terms of the particle size distribution, regardless of the treating agent used. Therefore, it can be concluded that such a surface modification treatment improves the ordering of the layered structure only, but barely affects the morphology.

The structure and morphology of the pristine material, AST and APST were further characterized by transmission electron microscopy (TEM). Fig. 3 shows the information on the change at the surface after the pristine $\mathrm{Li}_{1.2} \mathrm{Ni}_{0.13} \mathrm{Co}_{0.13} \mathrm{Mn}_{0.54} \mathrm{O}_{2}$ material is modified. The bright field images shown in Fig. 3(d)-(f) suggest an obvious change in the outer layer of the particles after the $\mathrm{Li}_{1.2} \mathrm{Ni}_{0.13} \mathrm{Co}_{0.13} \mathrm{Mn}_{0.54} \mathrm{O}_{2}$ material is surface treated. More specifically, when the sample is modified, the outer layer becomes different from the previous one. A rough layer appears and deepens as the degree of treatment increases. Scratches and pores can be visibly seen as a result of corrosion and some component loss from the outer layer (see Fig. S2 $\dagger$ ).

High-resolution transmission electron microscopy (HRTEM) images are shown in the insets of Fig. 4(a) and (b). There appear a clear spinel outer layer, layered bulk and a transition region. The outer layer has a lattice spacing of $0.29 \mathrm{~nm}$, which is in great accordance with the (220) plane along with [-111] of the spinel phase, while the inner layer shows that of $0.47 \mathrm{~nm}$. The lattice spacing of $0.47 \mathrm{~nm}$ should be ascribed to the (003) plane in layered-LiMO $\mathrm{L}_{2}$ or (111) in spinel $\mathrm{LiM}_{2} \mathrm{O}_{4}$. The SAED pattern of APST in Fig. 4(b) shows the superimposition of characteristic patterns of the rhombohedral phase along the [0001] zone axis, monoclinic phase along the [103] zone axis, spinel phase along the $[-111]$ zone axis and forbidden $\{10-10\}$ reflection along the [0001] zone axis, which further confirms the coexistence of the spinel phase and original layered phase in one single particle. ${ }^{36,37}$ Meanwhile, the dark field image of APST is shown in Fig. S2, $\dagger$ in which the bright edge is conspicuous, indicating a definite transformation reaction taking place in the outer layer when $\mathrm{Li}_{1.2} \mathrm{Ni}_{0.13} \mathrm{Co}_{0.13} \mathrm{Mn}_{0.54} \mathrm{O}_{2}$ is treated with APS. Consequently, a new phase may have formed at the surface. It implies that the newly formed phase is uniformly and intimately connected to the inner part of the particle.

High-resolution TEM and fast Fourier transform (FFT) studies were performed to estimate the range of spinel phase, as shown in Fig. 4(c). As the (220) plane from the spinel phase can be clearly identified in zones (I), (II) and (III), but not in zone (IV), moreover, the bulk region in zone (IV) remains in the monoclinic and rhombohedral layered phases, the bulk layered, newly formed spinel outer layer as well as a transition region are demonstrated to coexist. Such results are also consistent with the HRTEM image and SAED pattern. ${ }^{38,39}$ The depth of the spinel layer should be several nanometres. It is also noticed that when a smaller amount of APS is used, the depth of the spinel layer decreases (see Fig. S3†). So we predict that the outer layer is easily controlled and adjusted.

To understand the newly formed phase in the outer layer, energy-dispersive X-ray spectroscopy (EDS) was employed to investigate the composition. Fig. 4(d) and (e) show each spot on the same particle (e) and the corresponding content of $\mathrm{Ni} / \mathrm{Co} /$ $\mathrm{Mn}$ in different nano-domains (d). Since the Mn content remains constant in different nano-domains, it is normalized to 100 , and on the basis of that, it is easy to figure out that Co escaped from the surface of the particle and finally formed a structure with different compositions in the surface nanodomain. The element distribution implies no Mn and Ni loss

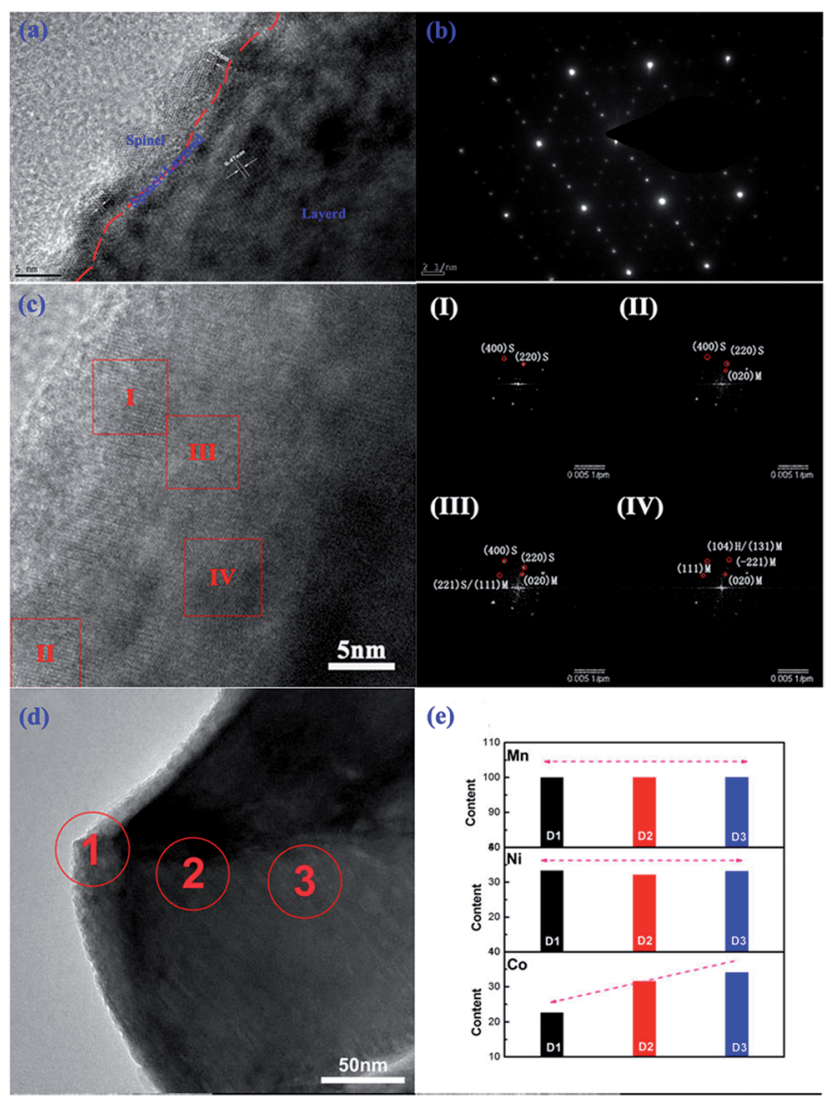

Fig. 4 (a) HRTEM image of APST, (b) SAED pattern of APST, and (c) HRTEM image of a single APST particle, with FFT images corresponding to different nano-domains; EDS collecting spot on one particle (d) and the corresponding content of $\mathrm{Mn} / \mathrm{Ni} / \mathrm{Co}(\mathrm{e})$. 

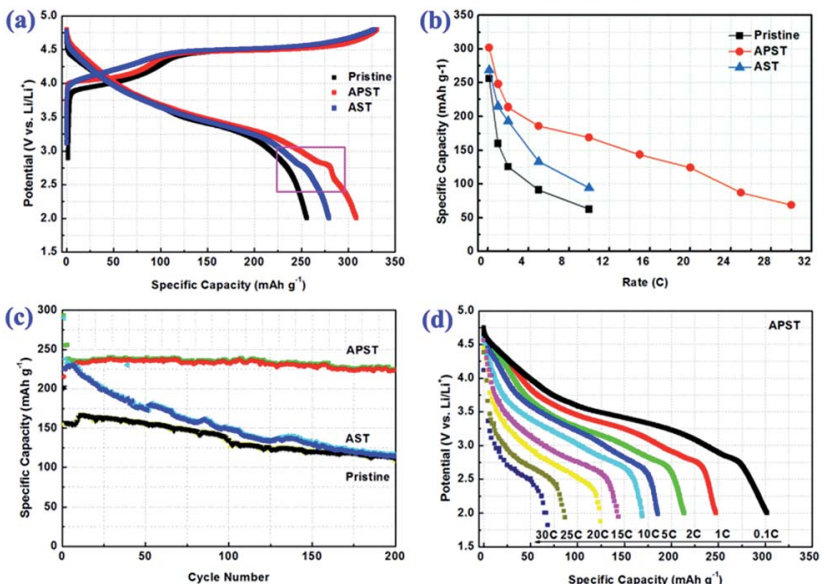

Fig. 5 Electrochemical performances of pristine $\mathrm{Li}_{1.2} \mathrm{Ni}_{0.13} \mathrm{CO}_{0.13}$ $\mathrm{Mn}_{0.54} \mathrm{O}_{2}$, APST and AST, (a) the charge/discharge curves at $0.1 \mathrm{C}$; (c) the cycle performance tested at $1 \mathrm{C}$; $(\mathrm{b}$ and $\mathrm{d})$ rate capability $(1 \mathrm{C}=$ $200 \mathrm{~mA} \mathrm{~h} \mathrm{~g}^{-1}$ ).

through the treatment. Therefore, we correspondingly infer that the bulk remains the same as the untreated one, and the newly formed phase in the outer layer of APST is with a composition of around $\mathrm{Mn}: \mathrm{Co}: \mathrm{Ni}=0.64: 0.15: 0.21$. On the other hand, for pristine $\mathrm{Li}_{1.2} \mathrm{Ni}_{0.13} \mathrm{Co}_{0.13} \mathrm{Mn}_{0.54} \mathrm{O}_{2}$ and $\mathrm{AST}$, the ratio of $\mathrm{Co} / \mathrm{Ni} /$ $\mathrm{Mn}$ remains constant from the bulk to the surface. Although we are not very clear about the virtual reaction mechanism between APS and $\mathrm{Li}_{1.2} \mathrm{Ni}_{0.13} \mathrm{Co}_{0.13} \mathrm{Mn}_{0.54} \mathrm{O}_{2}$, it is reasonable to speculate that $\mathrm{Ni}^{2+}$ is partially oxidized to $\mathrm{Ni}^{3+}$ by the strong oxidant APS. Correspondingly, Co leaves the particle due to charge compensation. Such a surface modification process can introduce oxidized Ni through a hydrothermal reaction which has been reported by Choy et $a l^{40}$

Fig. 5 shows the electrochemical performances of the pristine $\mathrm{Li}_{1.2} \mathrm{Ni}_{0.13} \mathrm{Co}_{0.13} \mathrm{Mn}_{0.54} \mathrm{O}_{2}$ and modified samples, which were collected at different current densities $\left(1 \mathrm{C}=200 \mathrm{~mA} \mathrm{~g}^{-1}\right)$. As shown in Fig. 5(a), all charge/discharge curves of the pristine and modified samples show typical characteristics of a layered Li-rich material. A plateau appears around $4.5 \mathrm{~V}$ in the first charge profile, which has been mainly attributed to a loss of oxygen from the layered lattice. ${ }^{41}$ When $\mathrm{Li}_{1.2} \mathrm{Ni}_{0.13} \mathrm{Co}_{0.13} \mathrm{Mn}_{0.54} \mathrm{O}_{2}$ is treated with APS or AS, it delivers a much larger capacity and shows a rather large coulombic efficiency for the first cycle compared to that of the pristine $\mathrm{Li}_{1.2} \mathrm{Ni}_{0.13} \mathrm{Co}_{0.13} \mathrm{Mn}_{0.54} \mathrm{O}_{2}$. The pristine $\mathrm{Li}_{1.2} \mathrm{Ni}_{0.13} \mathrm{Co}_{0.13} \mathrm{Mn}_{0.54} \mathrm{O}_{2}$ delivers a discharge capacity of $255.87 \mathrm{~mA} \mathrm{~h} \mathrm{~g}{ }^{-1}$, while AST and APST show that of $275.20 \mathrm{~mA} \mathrm{~h} \mathrm{~g}^{-1}$ and $308.71 \mathrm{~mA} \mathrm{~h} \mathrm{~g}^{-1}$, respectively. Meanwhile, an increase of the coulombic efficiency at the first cycle is obtained, that is, $77.7 \%$ for the pristine $\mathrm{Li}_{1.2} \mathrm{Ni}_{0.13} \mathrm{Co}_{0.13} \mathrm{Mn}_{0.54} \mathrm{O}_{2}$, 85.5\% for AST, and $93.4 \%$ for APST. Such improvements could be attributed to the two aspects brought in by the transformation reaction of the layered to spinel outer layer. During the surface modification reaction, a portion of $\mathrm{Li}^{+}$is pre-extracted. Meanwhile the $\mathrm{Li}^{+}$insertion process is highly promoted. ${ }^{42}$

Additionally, an inflexion appearing around $2.8 \mathrm{~V}$ can be observed in all curves of the modified samples. Such an inflexion has been reported as a characteristic of the spinel structure, which contributes to the improvement of the electrochemical performance especially the rate capability. ${ }^{43}$ Among all the samples, APST shows the best rate capability. As shown in Fig. 5(b) and (d), it exhibits a discharge capacity of $169.1 \mathrm{~mA} \mathrm{~h} \mathrm{~g}^{-1}$ at $10 \mathrm{C}$, which is much larger than $64.1 \mathrm{~mA} \mathrm{~h} \mathrm{~g}^{-1}$ of the pristine material. Furthermore, APST even displays a discharge capacity of $100.8 \mathrm{~mA} \mathrm{~h} \mathrm{~g}^{-1}$ and $68.2 \mathrm{~mA} \mathrm{~h} \mathrm{~g}^{-1}$ at $20 \mathrm{C}$ and $30 \mathrm{C}$, respectively. The best rate capability of APST should be ascribed to the spinel outer layer with suitable depth and element compositions for faster $\mathrm{Li}^{+}$diffusion.

Fig. 5(c) displays the cycling performance of the pristine $\mathrm{Li}_{1.2} \mathrm{Ni}_{0.13} \mathrm{Co}_{0.13} \mathrm{Mn}_{0.54} \mathrm{O}_{2}$ and modified samples at $1 \mathrm{C}$. After 200 cycles, the capacities remain at $111.1 \mathrm{~mA} \mathrm{~h} \mathrm{~g}^{-1}$ and $117.7 \mathrm{~mA} \mathrm{~h} \mathrm{~g}^{-1}$ for the pristine sample and AST, respectively, while APST shows the best capacity retention among all. It still exhibits a capacity of $223.1 \mathrm{~mA} \mathrm{~h} \mathrm{~g}^{-1}$, which means almost no capacity decay after the prolonged 200 cycles.

The outstanding electrochemical performances of APST that cover low irreversible capacity loss (IRCL) in the initial cycles, good rate capability and amazing cyclability should be attributed to the as-obtained layered-spinel structure. We affirmed that a suitable degree of treatment helped yield an appropriate composite structure benefiting the electrochemical performance. When comparing APST with AST, it seems that both can promote a spinel phase in the particle which leads to a better rate capability. The APS treated material exhibited great cycle performance, while the AS treated sample showed little improvement.

EIS measurements were carried out on the pristine and surface-modified samples. Before the measurements, cells were galvanostatically charged/discharged to the desired cycles. According to the previous EIS studies on this type of layered oxide cathode, Nyquist plots were fitted to the model in Fig. 6(a). Generally, Nyquist plots include three parts, a semicircle in the high frequency range corresponding to the $R_{\mathrm{s}}$ (the impedance of the natural and artificial solid electrolyte interface and the impedance of electrons through the active materials) in the model, a semicircle in the medium-to-low frequency range which corresponds to the $R_{\mathrm{ct}}$ (charge-discharge resistance at the interface of the electrode and electrolyte) and a sloping line at low frequency which corresponds to $Z_{\mathrm{w}}$ (diffusion of lithium ions in the solid electrode). ${ }^{\mathbf{4 4 , 4 5}}$

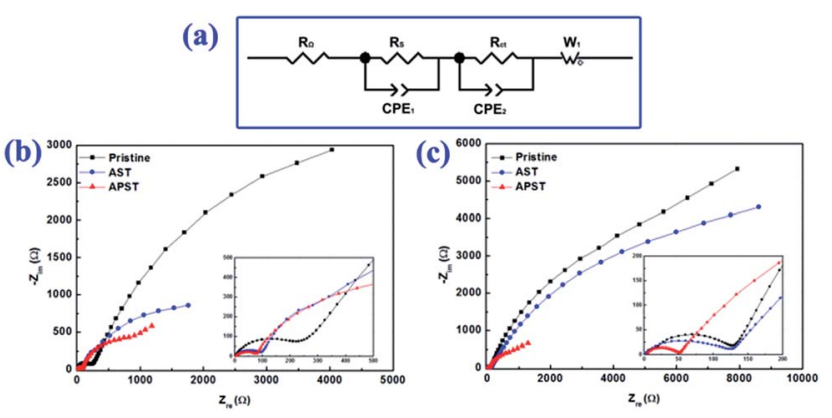

Fig. 6 EIS of pristine $\mathrm{Li}_{1.2} \mathrm{Ni}_{0.13} \mathrm{CO}_{0.13} \mathrm{Mn}_{0.54} \mathrm{O}_{2}$, AST and APST, (a) the equivalent circuit, (b) after 1 cycle of charge/discharge, and (c) after 200 cycles of charge/discharge. 
As the value of $R_{\mathrm{s}}$ is quite small, the ohmic polarization of these investigated samples is negligible. Also, since this strategy of surface modification does not change the particle size and crystallographic structure much, $Z_{\mathrm{w}}$ and the diffusion polarization of the pristine and modified samples remain nearly unchanged. Therefore, the differences in rate capabilities between the pristine and surface-modified samples should arise mainly from the differences in the charge transfer polarization provided by the different $R_{\mathrm{ct}}$ values.

Obviously, both modified samples show a much smaller $R_{\mathrm{ct}}$ compared with the pristine material after the first cycle of charge/discharge, and the $R_{\text {ct }}$ value decreases in the order: pristine $\mathrm{Li}_{1.2} \mathrm{Ni}_{0.13} \mathrm{Co}_{0.13} \mathrm{Mn}_{0.54} \mathrm{O}_{2}>$ AST $>$ APST, which is in exact accordance with the rate capability of these samples. Therefore we ensure that the spinel phase improved the rate capability by decreasing the charge transfer resistance.

The $R_{\mathrm{ct}}$ values of the pristine sample and AST become much higher after the 200th cycle than that of APST. However, the $R_{\mathrm{ct}}$ of APST increases very little. These EIS results clearly indicate that the APS treatment significantly suppresses the increase of $R_{\text {ct }}$ with cycling. Since the increase of $R_{\text {ct }}$ of $\mathrm{Li}_{1.2} \mathrm{Ni}_{0.13} \mathrm{Co}_{0.13^{-}}$ $\mathrm{Mn}_{0.54} \mathrm{O}_{2}$ is mainly caused by side-reactions between the electrode and the electrolyte, we infer that such an APS modified structure effectively protects the electrode from side reactions with the electrolyte. Furthermore, the difference in the AST outer layer and APST outer layer should contribute to the lower $R_{\mathrm{s}}$ and $R_{\mathrm{ct}}$, and consequently the superior electrochemical performance.

The XPS spectra and fitting spectra of Ni 2p of the pristine, APST and AST samples are displayed in Fig. 7 to demonstrate the variations in the chemical states. XPS data were obtained at the surface within a depth of $5-10 \mathrm{~nm}$. The pristine $\mathrm{Li}_{1.2} \mathrm{Ni}_{0.13}$ $\mathrm{Co}_{0.13} \mathrm{Mn}_{0.54} \mathrm{O}_{2}$, AST and APST show typical peaks of $\mathrm{Li}, \mathrm{Ni}, \mathrm{Co}$, $\mathrm{Mn}$ and $\mathrm{O}$ in Fig. 7(a), and they appear similar to each other. Since the binding energy of the Ni(III) $2 p$ orbital $(856.0 \mathrm{eV})$ is higher than that of $\mathrm{Ni}(\mathrm{II})(855.0 \mathrm{eV}),{ }^{46-48}$ it is reasonable to deduce the content of $\mathrm{Ni}^{3+}$ and $\mathrm{Ni}^{2+}$ from the $\mathrm{Ni}$ fitting spectra
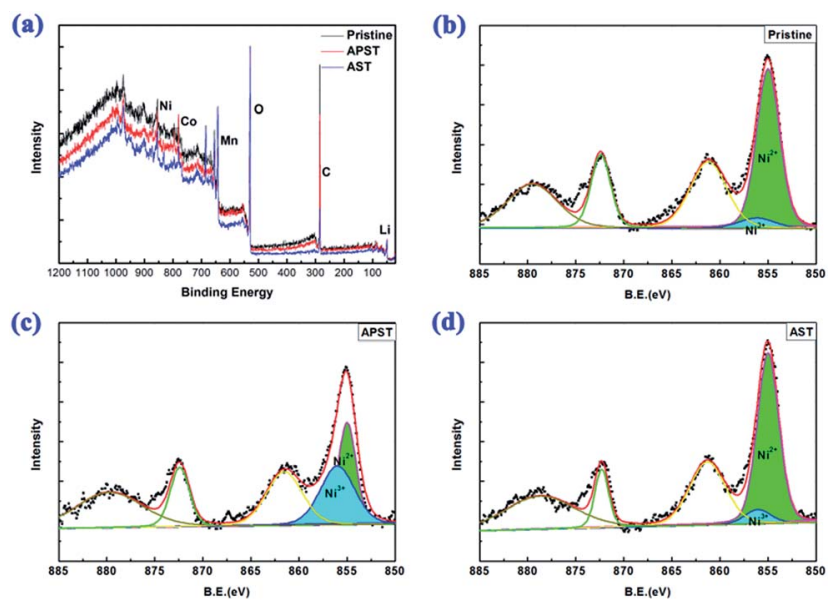

Fig. 7 (a) XPS spectra of the pristine $\mathrm{Li}_{1.2} \mathrm{Ni}_{0.13} \mathrm{CO}_{0.13} \mathrm{Mn}_{0.54} \mathrm{O}_{2}$, APST and AST samples and Ni fitting spectra of (b) pristine, (c) APST and (d) AST.
Table 1 Peak intensity of $\mathrm{Ni}^{3+}$ and $\mathrm{Ni}^{2+}$ and intensity ratio of $\mathrm{Ni}^{3+} / \mathrm{Ni}^{2+}$ in the pristine $\mathrm{Li}_{1.2} \mathrm{Ni}_{0.13} \mathrm{CO}_{0.13} \mathrm{Mn}_{0.54} \mathrm{O}_{2}$, APST and AST

\begin{tabular}{llrl}
\hline & $I(855.0)$ & $I(856.0)$ & $I(856.0) / I(855.0)$ \\
\hline Pristine & 665.6 & 67.0 & 0.10 \\
APST & 328.5 & 359.8 & 1.10 \\
AST & 661.3 & 66.6 & 0.11
\end{tabular}

of pristine $\mathrm{Li}_{1.2} \mathrm{Ni}_{0.13} \mathrm{Co}_{0.13} \mathrm{Mn}_{0.54} \mathrm{O}_{2}$, APST and AST as shown in Fig. 7(b)-(d). It can be obviously seen that the content of $\mathrm{Ni}^{3+}$ in APST increases to a large extent compared to that with the pristine $\mathrm{Li}_{1.2} \mathrm{Ni}_{0.13} \mathrm{Co}_{0.13} \mathrm{Mn}_{0.54} \mathrm{O}_{2}$ and AST.

Via the peak integral on $\mathrm{Ni}(\mathrm{II})$ and $\mathrm{Ni}(\mathrm{III})$, we find that the ratio of $\mathrm{Ni}^{3+} / \mathrm{Ni}^{2+}$ in APST rises up to 1.10, while that of AST remains around 0.11 , which is similar to 0.10 of the pristine (Table 1). Based on the XPS spectral analysis, it is confirmed that $\mathrm{Ni}^{3+}$ is rich in the newly formed spinel outer layer at a depth of $5-10 \mathrm{~nm}$, which is in good agreement with the HRTEM and EDS results. The important role that $\mathrm{Ni}^{3+}$ plays in APST should be noticed. Such an oxidized spinel outer layer with $\mathrm{Ni}^{3+}$ performs much better in facilitating $\mathrm{Li}^{+}$intercalation/deintercalation and steadying the material during prolonged charge/discharge tests.

\section{Conclusions}

An oxidized spinel phase can be fabricated in the outer layer of $\mathrm{Li}_{1.2} \mathrm{Ni}_{0.13} \mathrm{Co}_{0.13} \mathrm{Mn}_{0.54} \mathrm{O}_{2}$ through a facile and feasible surface treatment with APS, and it contains a very large amount of $\mathrm{Ni}^{3+}$. Such a spinel outer layer with $\mathrm{Ni}^{3+}$ is proved to enormously benefit the electrochemical performance of layered Li-rich cathode materials. In the case of the as-treated Li-rich cathode material, a certain proportion of $\mathrm{Li}^{+}$is pre-extracted from the bulk during the pre-treatment which should be responsible for the larger coulombic efficiency in the initial cycle. The 3D $\mathrm{Li}^{+}$ pathway of the spinel outer layer can facilitate Li diffusion, and decreases the charge transfer resistance a lot, leading to a great rate capability. More importantly, an oxidized spinel outer layer with $\mathrm{Ni}^{3+}$ is well compatible with the layered bulk $\mathrm{Li}_{1.2} \mathrm{Ni}_{0.13}$ $\mathrm{Co}_{0.13} \mathrm{Mn}_{0.54} \mathrm{O}_{2}$, and it protects the active material from invasion of electrolyte components and helps steady the cathode material after hundreds of charge/discharge cycles.

\section{Acknowledgements}

We gratefully acknowledge the financial support from the Key Project of NSFC (U1305246, 21321062), the National 973 Program (2009CB251102) and the NFFTBS (no. J1310024), and the eleventh YUMIAO fund of Xiamen University (20130606).

\section{References}

1 M. Armand and J. M. Tarascon, Nature, 2008, 451, 652-657.

2 M. S. Zheng, J. J. Chen and Q. F. Dong, Adv. Mater. Res., 2012, 476, 676-680. 
3 J. Ma, B. Li, H. Du, C. Xu and F. Kang, J. Solid State Electrochem., 2012, 16, 1-8.

4 Z. Lu, D. MacNeil and J. Dahn, Electrochem. Solid-State Lett., 2001, 4, A191-A194.

5 M. M. Thackeray, S.-H. Kang, C. S. Johnson, J. T. Vaughey, R. Benedek and S. A. Hackney, J. Mater. Chem., 2007, 17, 3112-3125.

6 J. Fan, J. Chen, Y. Chen, H. Huang, Z. Wei, M.-s. Zheng and Q. Dong, J. Mater. Chem. A, 2014, 2, 4870-4873.

7 C. Johnson, N. Li, C. Lefief and M. Thackeray, Electrochem. Commun., 2007, 9, 787-795.

8 J. Zheng, S. Deng, Z. Shi, H. Xu, H. Xu, Y. Deng, Z. Zhang and G. Chen, J. Power Sources, 2013, 221, 108-113.

9 Y. Chen, K. Xie, C. Zheng, Z. Ma and Z. Chen, ACS Appl. Mater. Interfaces, 2014, 6, 16888-16894.

10 B. Kang and G. Ceder, Nature, 2009, 458, 190-193.

11 F. Lin, I. M. Markus, D. Nordlund, T.-C. Weng, M. D. Asta, H. L. Xin and M. M. Doeff, Nat. Commun., 2014, 5, DOI: 10.1038/ncomms4529.

12 G. Singh, R. Thomas, A. Kumar, R. Katiyar and A. Manivannan, J. Electrochem. Soc., 2012, 159, A470-A478.

13 H. Ming, Y. Yan, J. Ming, J. Adkins, X. Li, Q. Zhou and J. Zheng, Electrochim. Acta, 2014, 120, 390-397.

14 S. Shi, J. Tu, Y. Zhang, Y. Zhang, X. Zhao, X. Wang and C. Gu, Electrochim. Acta, 2013, 108, 441-448.

15 J. Zheng, Z. Zhang, X. Wu, Z. Dong, Z. Zhu and Y. Yang, J. Electrochem. Soc., 2008, 155, A775-A782.

16 G. Xu, J. Li, Q. Xue, Y. Dai, H. Zhou, X. Wang and F. Kang, Electrochim. Acta, 2014, 117, 41-47.

17 H. Zhang and T. Song, Electrochim. Acta, 2013, 114, 116-124.

18 X. Guan, B. Ding, X. Liu, J. Zhu, C. Mi and X. Zhang, J. Solid State Electrochem., 2013, 17, 2087-2093.

19 J. Liu and A. Manthiram, J. Mater. Chem., 2010, 20, 39613967.

20 A. Abouimrane, O. C. Compton, H. Deng, I. Belharouak, D. A. Dikin, S. T. Nguyen and K. Amine, Electrochem. SolidState Lett., 2011, 14, A126-A129.

21 J.-S. Kim, C. Johnson, J. Vaughey and M. Thackeray, J. Power Sources, 2006, 153, 258-264.

22 V. Voronov and S. Gubin, Inorg. Mater., 2014, 50, 409-414.

23 Y. Denis, K. Yanagida and H. Nakamura, J. Electrochem. Soc., 2010, 157, A1177-A1182.

24 F. Wu, N. Li, Y. Su, H. Shou, L. Bao, W. Yang, L. Zhang, R. An and S. Chen, Adv. Mater., 2013, 25, 3722-3726.

25 Y. Oumellal, A. Rougier, G. Nazri, J. Tarascon and L. Aymard, Nat. Mater., 2008, 7, 916-921.

26 D. Wang, I. Belharouak, G. Zhou and K. Amine, Adv. Funct. Mater., 2013, 23, 1070-1075.

27 Y.-K. Sun, M.-J. Lee, C. S. Yoon, J. Hassoun, K. Amine and B. Scrosati, Adv. Mater., 2012, 24, 1192-1196.
28 F. Wu, N. Li, Y. Su, L. Zhang, L. Bao, J. Wang, L. Chen, Y. Zheng, L. Dai, J. Peng and S. Chen, Nano Lett., 2014, 14, 3550-3555.

29 B. Song, H. Liu, Z. Liu, P. Xiao, M. O. Lai and L. Lu, Sci. Rep., 2013, 3, DOI: 10.1038/srep03094.

30 J. Zheng, J.-J. Chen, X. Jia, J. Song, C. Wang, M.-S. Zheng and Q.-F. Dong, J. Electrochem. Soc., 2010, 157, A702-A706.

31 D. H. Park, S. T. Lim, S. J. Hwang, C. S. Yoon, Y. K. Sun and J. H. Choy, Adv. Mater., 2005, 17, 2834-2837.

32 Y. Paik, C. P. Grey, C. S. Johnson, J. S. Kim and M. M. Thackeray, Chem. Mater., 2002, 14(12), 5109-5115.

33 D. H. Park, S. H. Lee, T. W. Kim, S. T. Lim, S. J. Hwang, Y. S. Yoon, Y. H. Lee and J. H. Choy, Adv. Funct. Mater., 2007, 17, 2949-2956.

34 B. R. Long, J. R. Croy, F. Dogan, M. R. Suchomel, B. Key, J. Wen, D. J. Miller, M. M. Thackeray and M. Balasubramanian, Chem. Mater., 2014, 26, 3565-3572.

35 J. Liu, M. Hou, J. Yi, S. Guo, C. Wang and Y. Xia, Energy Environ. Sci., 2014, 7, 705-714.

36 S.-K. Jung, H. Gwon, J. Hong, K.-Y. Park, D.-H. Seo, H. Kim, J. Hyun, W. Yang and K. Kang, Adv. Energy Mater., 2014, DOI: 10.1002/aenm.201300787.

37 N. P. Pieczonka, Z. Liu, P. Lu, K. L. Olson, J. Moote, B. R. Powell and J.-H. Kim, J. Phys. Chem. C, 2013, 117, 15947-15957.

38 D. Mohanty, S. Kalnaus, R. A. Meisner, A. S. Safat, J. Li, E. A. Payzant, K. Rhodes, I. I. I. D. L. Wood and C. Daniel, RSC Adv., 2013, 3, 7479-7485.

39 B. Xu, C. R. Fell, M. Chi and Y. S. Meng, Energy Environ. Sci., 2011, 4, 2223-2233.

40 D. H. Park, S. T. Lim, S. J. Hwang, C. S. Yoon, Y. K. Sun and J. H. Choy, Adv. Mater., 2005, 17, 2834-2837.

41 A. Boulineau, L. Simonin, J.-F. Colin, E. Canévet, L. Daniel and S. Patoux, Chem. Mater., 2012, 24, 3558-3566.

42 B. Li, Q. Wang, Y. Zhang, Z. Song and D. Yang, Int. J. Electrochem. Sci., 2013, 8, 5396-5406.

43 C. Liu, Z. Wang, C. Shi, E. Liu, C. He and N. Zhao, ACS Appl. Mater. Interfaces, 2014, 6, 8363-8368.

44 L. A. Riley, S. Van Atta, A. S. Cavanagh, Y. Yan, S. M. George, P. Liu, A. C. Dillon and S. H. Lee, J. Power Sources, 2011, 196, 3317.

45 Z. Li, F. Du, X. Bie, D. Zhang, Y. Cai, X. Cui, C. Wang, G. Chen and Y. Wei, J. Phys. Chem. C, 2010, 114, 22751-22757.

46 J. Yu, S. Wang, B. Cheng, Z. Lin and F. Huang, Catal. Sci. Technol., 2013, 3, 1782-1789.

47 G. Cherkashinin, D. Ensling, P. Komissinskiy, R. Hausbrand and W. Jaegermann, Surf. Sci., 2013, 608, L1-L4.

48 Y. Cho, P. Oh and J. Cho, Nano Lett., 2013, 13, 1145-1152. 